\title{
NOTAS SOBRE LA PIZARRA MÁGICA FUEGUINA
}

\author{
CAROLINA ODONE ${ }^{a} \&$ PETER MASON ${ }^{b}$
}

\begin{abstract}
RESUMEN
En este trabajo, inevitablemente fragmentario, abordaremos algunos ejemplos de la presencia del mundo fueguino en la coyuntura europea de los años 20 -sobre todo en las exposiciones misionarias-, y otros ejemplos contemporáneos de la presencia de representantes o representaciones del mundo europeo en Tierra del Fuego -por citar, el viaje del crucero Italia en 1924-, para demostrar la porosidad que existía a ambos lados de la línea divisoria. En el momento explosivo del surrealismo en Europa -la misma década en que Sigmund Freud publicó su Nota sobre la pizarra mágica-, las exposiciones europeas valorizaron los artefactos de las culturas fueguinas sometidas al azote del viento, los océanos y los hombres venidos del Viejo Mundo.
\end{abstract}

PALABRAS CLAVE: surrealismo, misiones y exposiciones misionarias, alteridad.

\section{NOTES ON THE FUEGIAN WUNDERBLOCK}

\begin{abstract}
In this inevitably fragmentary presentation, examples of the presence of the Fuegian world in the European conjuncture of the 1920s -above all in the missionary exhibitions-, and contemporary examples of the presence of representatives or representations of the European world in Tierra del Fuego -viz. the voyage of the cruiser Italia in 1924-, are discussed to show the porosity of the line dividing them. In the moment when Surrealism exploded in Europe -the same decade in which Sigmund Freud published his Note on the Wunderblock-, the European exhibitions showed an appreciation of the artefacts of Fuegian cultures that were themselves subject to the erosive effects of the wind, the oceans and the men who came from the Old World.
\end{abstract}

KEY WORDS: Surrealism, missions and missionary exhibitions, alterity. 


\section{PRÓLOGO}

¡La maldición cae sobre ella! Y a la Tartaria la mando, y de allí a la Tierra del Fuego, y así sucesivamente hasta al diablo: en suma, ¡no queda un solo nicho del averno al que no envíe yo a su divinidad!

L. Sterne, The Life \& Opinions of Tristram Shandy, 1759-1767.

Este pasaje de la crónica de los amores de la Viuda Wadman y el Tío Toby contiene un gradual in crescendo de la maldición que pronuncia el narrador, Tristram Shandy, sobre su amante. La condena se inicia con el deseo de mandarla a Tartaria, y antes de llegar al punto culminante del diablo, se le ocurre como mejor punto entre dos extremos, la Tierra del Fuego, mentalmente más lejos que Tartaria y moralmente menos repugnante que el diablo.

El octavo volumen de Las Vidas y Opiniones del caballero Tristram Shandy fue publicado en 1765, el mismo año en que el comodoro John Byron tomó posesión solemnemente de las islas Falkland/Malvinas para la corona británica. Ese octavo volumen era un testimonio de que, en la segunda mitad del siglo XVIII, la Tierra del Fuego se había asegurado un lugar prominente en la literatura inglesa y por extensión en el imaginario europeo. Era el lugar sinónimo del triste destino de exilio, tal como volvería a ser en los años $70 \mathrm{del}$ siglo pasado, cuando en isla Dawson, en el estrecho de Magallanes, se levantaron dos campamentos de encierro forzoso para presos políticos de la Unidad Popular, los campos de internación de Río Chico y Compingim (Compañía de Ingenieros de la Infantería de Marina), que funcionaron entre septiembre de 1973 y octubre de 1974.

En su libro Paisaje con figuras, Marta Penhos relata un triste desastre acontecido al inicio del año 1827 cuando el cúter en que viajaban un oficial a

1 Penhos, 2018. Paisaje con figuras. La invención de Tierra del Fuego a bordo del Beagle (1826-1836). Ampersand, Buenos Aires, p. 51.

2 Ibidem, p. 55. Asimismo, treinta años después, cuando Luis Piedrabuena se instaló en la isla Pavón sobre el río Santa Cruz -paradero de los tehuelches, situado entre las culturas chilenas y argentinas- construyó su "casa de piratas" utilizando los restos de naufragios de buques. Véase Sosa, 2015. Cazadores de plumas en la Patagonia. Singulares intercambios entre Tehuelches y Cristianos. Patagonia bordo del Adventure comandado por Phillip Parker King y los dos tripulantes que le acompañaban, se volcó ${ }^{1}$. Un año después, los viajeros británicos descubrieron restos del cúter usados como materiales de unas chozas fueguinas ${ }^{2}$. Podemos tomar este ejemplo de un artefacto indígena (la choza) que incorpora los restos de un artefacto europeo (el cúter) como modelo emblemático de la imbricación de elementos indígenas y europeos en el discurso sobre Tierra del Fuego, donde el mismo trozo de tierra es un espacio distinto para el viajero, el colono, el artista, el misionero, el científico ${ }^{3}, \mathrm{y}$, podríamos añadir, para el fueguino.

Muchas de las lecturas de las relaciones entre los pueblos indígenas de Tierra del Fuego han seguido el modelo (a veces derivado de la semiótica de Ferdinand de Saussure) de imágenes inversas ${ }^{4}$. En este juego de espejos, un mismo esencialista mira a un otro igualmente esencialista. Aplicado a nuestro caso, los europeos miran a los fueguinos desde un lado de una barrera invisible, mientras los fueguinos hacen lo propio (lo mismo) contemplando a los europeos desde el otro.

La realidad, sin embargo, como nos enseñan los ejemplos de Tristram Shandy y del cúter reciclado, es más opaca y enredada. No consiste en distinciones nítidas, sino en fronteras que van desplazándose continuamente. Elementos del mismo se encuentran en el otro, $y$ viceversa ${ }^{5}$. No existe alguna entidad socio-cultural, en contextos de encuentro cultural desigual, que no esté mediada por estas operaciones de transposiciones. Por tanto, la choza fueguina resulta ser una construcción híbrida o transcultural.

Pero no solo los objetos de cultura material vivieron este proceso. También el territorio fueguino fue dotado de una variedad de nombres con contenidos diversos y fundacionales: el extremo sur de Sudamérica, el fin del mundo, el último confín de la tierra, Tierra del Fuego o de los fuegos, el intermedio

Sur Libros, Buenos Aires, p. 23.

3 Sosa, 2015, op. cit., p. 35; Penhos, 2005. Ver, conocer, dominar. Imágenes de Sudamérica a fines del siglo XVIII. Siglo Veintiuno Editores, Buenos Aires.

4 Título del libro explícitamente de inspiración saussureana de Hawkins, 1984. Inverse Images: the meaning of culture, ethnicity and family in Postcolonial Guatemala. University of New Mexico Press, Albuquerque.

5 Mason, 1990. Deconstructing America. Representations of the Other. Routledge, Londres y Nueva York. 


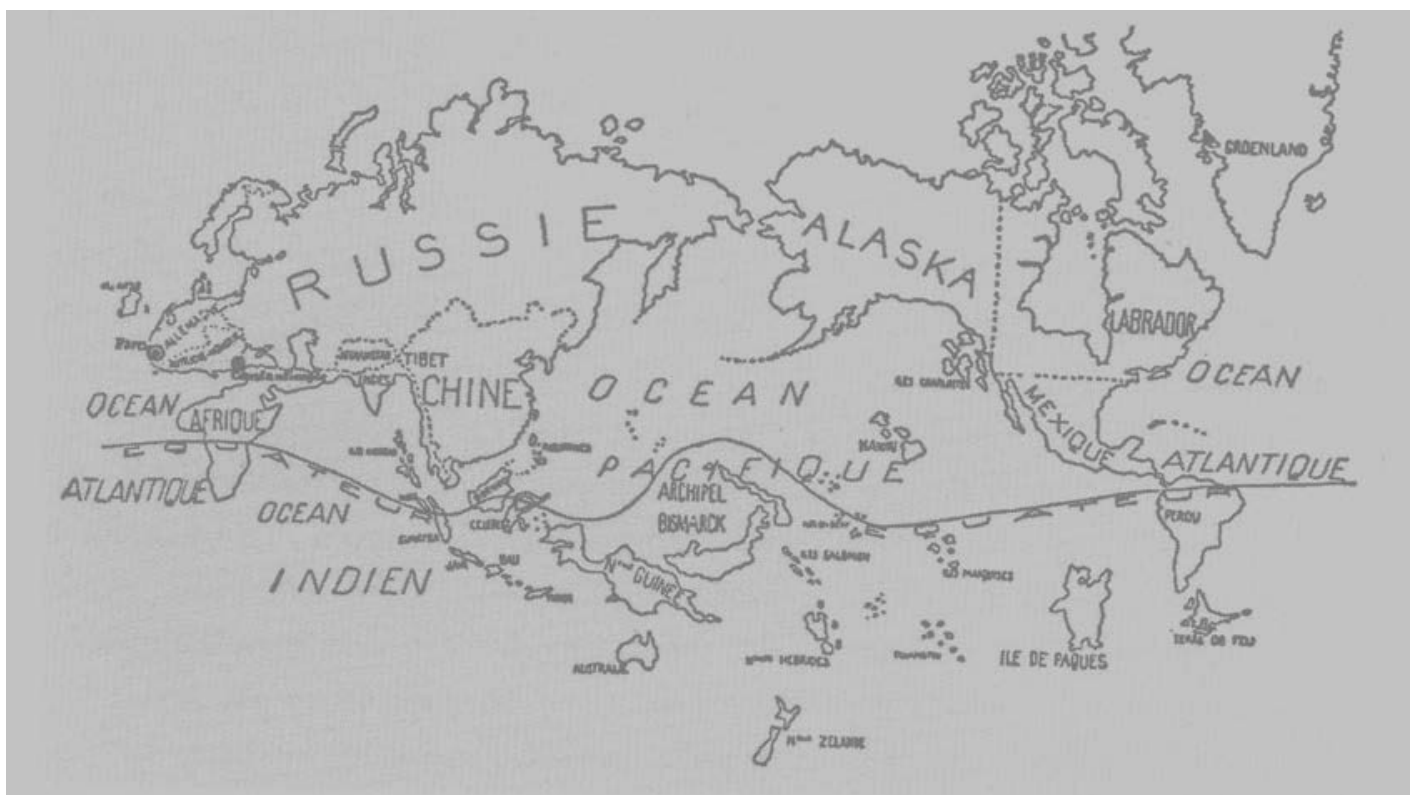

Fig. 1. Mapamundi surrealista publicado en Variétés, 1929.

entre Tartaria y el diablo... En este sentido, la metáfora más apropiada no sería la del espejo, sino la pantalla, ese soporte sobre el cual se proyectan los deseos y las pulsiones del inconsciente, la pizarra mágica (Wunderblock) en que se registran y se borran las memorias y de la que Freud hablaba en los años $20^{6}$. Ya después de su viaje a las islas del oeste de Escocia en 1775, James Boswell previno contra la tentación de proyectar: Si no hemos explorado las regiones magallánicas, abstengámonos, sin embargo, de poblarlas con patagones ${ }^{7}$.

Ciertamente es el fin del mundo o el extremo sur del mundo habitado para quienes miran el mundo desde el hemisferio norte, pero para los fueguinos es, sencillamente, su casa, es karukinka:

Karukinka esa tierra que está por allá lejos. Sí, ésa es karuk. Estaría junta la tierra, si [la Isla Grande con el continente],

6 Freud, 1979 [1924]. Nota sobre la 'pizarra mágica'. Obras Completas. Vol. XIX. El yo y el ello, y otras obras (19231925). Amorrortu, Buenos Aires y Madrid.

7 Johnson y Boswell, 1976. Journey to the Hebrides. Canongate, Edinburgh, p. 105.

8 Ángela Loij, citado en Chapman, 2002. Fin de un mundo. Los selknam de Tierra del Fuego. Taller Experimental Cuerpos Pintados, Santiago, p. 50.

9 Ejemplo de una experiencia similar es el que corresponde al texto del primer poema de Amereida (1967), texto que relata las travesías de un grupo de arquitectos, poetas porque estaban cazando guanaco esa gente [los antiguos selk'nam], venían unas cuantas familias y llegarian donde estaba la tierra, creo [en] aquellos tiempos, años, siglos ya. Quedaron aislados ahí [en la Isla Grande]. Por un terremoto habrá sido que quedaron aislados en esta tierra. Pero éste [hace] siglos de años. Quedaron, hasta que aumentaron mucho. Sí, mucha gente. Ahí quedó karuk, sola sí. Karuk ${ }^{8}$.

En el mapa surrealista de 1929, el territorio de Tierra del Fuego se ha aumentado de tamaño, mientras que los Estados Unidos no aparecen como tales (Fig. 1). Representa, claro, una visión europea, la del movimiento surrealista, pero también significa, aunque involuntariamente, una Tierra del Fuego más próxima a la percepción de la misma por sus habitantes indígenas ${ }^{9}$. Dado que el surrealismo

y artistas de la Escuela de Arquitectura de la Universidad Católica de Valparaíso que, a fines de la década de 1950, en una serie de viajes miraron América del Sur desde la Cruz del Sur, comenzando su viaje desde la región del cabo de Hornos . O el dibujo del pintor uruguayo Joaquín Torres García, América Invertida (1943), que expresa su pensar: ya en otro tiempo volvimos el mapa al revés indicando que nuestro norte era el sur. Torres García, citado en Murlender, 2014. La escuela de Joaquín Torres-García y su tesis americanista: Buscar a América. Diversidad, 9, Año 5, pp. 43-59, p. 45. 
alcanzó su clímax en Europa en los años 20 del siglo veinte -los mismos años en que Freud iba a publicar su nota sobre la pizarra mágica-, indicaremos algunos ejemplos de la presencia del mundo fueguino en esta coyuntura europea y ejemplos contemporáneos de la presencia de representantes o representaciones del mundo europeo en Tierra del Fuego, para demostrar la porosidad que existía y existe a ambos lados de la línea divisoria. En este breve texto queremos explorar, a través de ciertos fragmentos, las posibilidades de mirar esta interacción desde dos puntos de vista a la vez, el europeo y el fueguino, ambos imbricados o enredados.

\section{FRAGMENTOS 1924-1925}

Sería difícil encontrar dos exposiciones tan distintas como las celebradas en las ciudades de París y Roma en el año 1925. Todos los ojos miraban hacia la capital francesa, donde desde abril hasta octubre, la modernidad estalló en todas sus facetas en la Exposition internationale des arts décoratifs et industriels modernes, presentando productos $y$ objetos tanto de inspiración exótica, arcaica y egipcia como vanguardista ${ }^{10}$. De un tenor muy distinto, el mismo año 1925 fue celebrado como Año Santo o Año Jubilar en la Ciudad Vaticana con la Esposizione Universale Missionaria, a la cual llegaron más de cien mil objetos, los que fueron expuestos en veinticuatro pabellones y en dos grandes galerías ${ }^{11}$. Actualmente, entre los materiales que se guardan en los Museos Vaticanos, se encuentran varios objetos fueguinos que tienen, en el ámbito europeo, una vida y exhibición pública porque formaron parte de ese proyecto misionero de muestra.

La Esposizione Universale Missionaria, un sueño del Papa Pío XI, fue inaugurada el 21

10 Benton, Benton y Wood (Eds.), 2003. Art Deco 19101939. Cat. exp. Victoria \& Albert Museum Londres, V\&A Publications, Londres. París, capital de la modernidad, se reflejó el mismo año de 1925 en la exposición Salón de Arte Libre en la Sala Rivas y Calvo en Santiago de Chile, donde artistas vanguardistas chilenos del Grupo Montparnasse, ya de vuelta de París, expusieron junto a artistas de primer plano de la vanguardia internacional, véase AA.VV., 2000. Chile 100 años artes visuales. Cat. exp. Museo Nacional de Bellas Artes, Santiago, Tomo I, pp. 79-90.

11 Pagnotta, 2018. La Exposición Misional Vaticana de 1925, los misioneros salesianos y la representación del Oriente de diciembre del año 1924 y duró hasta el 10 de enero de 1926. En Tierra del Fuego, el año de la inauguración de la Esposizione, sus habitantes nativos vivían las consecuencias devastadoras de una epidemia de sarampión:

Muertos, muertos, muertos. ¿Cuántos murieron? No sirve el Koliotxo'on [el médico blanco]. El cementerio está lleno. Tanta gente murió. Todos los días; todo el día muertos vienen, vienen en camiones llenos de muertos, mujeres, chicos. Todos murieron de koliot-kwaki [enfermedad de los blancos]; chiquitos juntos con sus mamás, pobrecitos. Sufren [sufrieron]. Señoritas, mujeres grandes no casadas todavía, muchachos jóvenes. El cementerio es grande ${ }^{12}$.

Se ha señalado que la Esposizione Universale Missionaria, puesta en escena de la labor misional de la Iglesia Católica en el mundo entero y anclada en las consecuencias de la Primera Guerra Mundial y en las reacciones al modernismo, buscaba un enfoque histórico, etnológico y también contemporáneo de la situación de las misiones católicas ${ }^{13}$.

Cuando la exposición llegó a su fin en 1926, los objetos que estaban expuestos fueron trasladados al nuevo Museo Missionario Etnologico, que tenía sede en el Palazzo Apostolico del Laterano, y en los años 70 del siglo XX, entraron a la nueva ala de los Museos Vaticanos. Entre los artefactos actualmente escondidos en el depósito de los Museos Vaticanos hay un modelo de choza utilizada en la ceremonia yámana llamada Chiexaus ${ }^{14}$, cuya forma imitaba la de una cueva en que se abrigaban los lobos

ecuatoriano. Procesos: Revista ecuatoriana de Historia 47, pp. 59-88, pp. 67-68.

12 Lola Kiepja, citado en Chapman, 2002, op cit., p. 34.

13 Sánchez Gómez, 2007. Por la etnología hacia Dios: La Exposición Misional Vaticana de 1925. Revista de Dialectología y Tradiciones Populares, Vol. LXII(2), pp. 63-107.

14 Sobre la ceremonia véase Chapman, 1997. The Great Ceremonies of the Selk'nam and the Yámana. A Comparative Analysis. En McEwan, Borrero y Prieto (Eds.). Patagonia, Natural History, prehistory and ethnography at the Uttermost End of the Earth. British Museum Press, London, pp. 82-109. 
marinos ${ }^{15}$. Un elenco de los objetos enviados para la Esposizione en el año 1924 lo describe como una pequeña piel de un joven lobo marino, por dividir en tres tiras trasversales para cubrir el pequeño modelo de la cabaña para la iniciación de los jóvenes ${ }^{16}$. La etiqueta en alemán e italiano lo define en los siguientes términos:

Un modelo de una cabaña sagrada en la cual los yáganes (América del Sur) celebran la consagración secreta de la juventud. En esta celebración solemne los y las jóvenes aprenden por medio de una instrucción que dura varias semanas cada obligación moral y social de su tribu. Estas obligaciones son todas relativas al Hitapuan ("mi padre"), el Ser Supremo17.

Se pueden comparar estas palabras con la definición de la catequesis que el Papa Juan Pablo II iba a enunciar algunas décadas más tarde:

La catequesis es una educación en la fe de los niños, de los jóvenes y adultos, que comprende especialmente una enseñanza de la doctrina cristiana, dada generalmente de modo orgánico y sistemático con miras a iniciarlos en la plenitud de la vida cristiana ${ }^{18}$.

En otras palabras, la etiqueta del modelo de la cabaña sagrada de la principal ceremonia de iniciación de los yámanas, en que los jóvenes de ambos sexos aprendían el comportamiento moral debido, las tradiciones orales y las tareas que iban a desempeñar en su vida adulta, incorpora esas prácticas fueguinas en un concepto doctrinal enunciado por la iglesia católica ${ }^{19}$. La presencia física del objeto yámana en la Ciudad Vaticana lo

15 Ibidem, p. 94.

16 Console, 2006. Le collezioni della Terra del Fuoco del Museo Missionario Etnologico Vaticano. En Salerno y Tagliacozzo (Eds.). Finis Terrae. Viaggiatori, esploratori e missionari italiani nella Terra del Fuoco. Cat. exp. Museo Nazionale Preistorico Etnografico "Luigi Pigorini", Ministero per i Beni e le Attività Culturali, Roma, pp. 295-309, p. 307.

17 El original es como sigue: Modello della sacra capanna nella quale i YAGAN (America del Sud) festeggiano la consecrazione segreta della gioventù. In questa sollenità si insegnano i ragazzi e le ragazze per mezzo di una istruzzione che dura parecchie settimane in ogni obbligo morale $e$ sociale della sua tribù. Questi obblighi sono tutti relativi al Hitapuan ('mio padre'), l'Essere Supremo. coloca en el caput mundi católico; la etiqueta coloca una ceremonia yámana en la doctrina cristiana.

Las palabras "Ser Supremo" (Höchste Wesen en el texto alemán) reflejan otro afán de los misioneros: la búsqueda en las culturas consideradas arcaicas de Tierra del Fuego de la prueba de que la forma original y pura de la región fuese el monoteísmo. Entre los exponentes más destacados de esta teoría podemos señalar a Wilhelm Koppers, quien acompañó a Martin Gusinde en la ceremonia de iniciación Chiexaus en marzo de $1922^{20}$, y al padre Wilhelm Schmidt, fundador del Wiener Kreis y futuro director del Museo Missionario Etnologico ${ }^{21}$. Otra vez, preocupaciones europeas de la época impactan en el mensaje transmitido por la etiqueta descriptiva de un objeto fueguino.

Lo interesante es que el padre Wilhelm Schmidt fue comisionado directamente por el Papa Pío XI, como el responsable o curador de la Sala de Etnología de la exposición vaticana de $1925^{22}$. En ese gran pabellón el padre Schmidt pudo no solo desarrollar, con entera libertad, su teoría de los círculos o ciclos culturales, sino también poner en un mismo lugar, es decir, en un contexto ajeno a ellos, los distintos objetos de cultura material que allí se exponían ${ }^{23}$.

En el mismo año en que viajaba y llegaba el modelo de la cabaña fueguina, la Chiexaus yámana, para ser exhibido para la Esposizione en Italia, un artista italiano arribaba a Tierra del Fuego. Bajo el auspicio del poeta más representativo del movimiento fascista Gabriele D'Annunzio y del duce Benito Mussolini, una nave de guerra, König Albert, había sido bautizada Italia, convertida en crucero y enviada a América Latina con la ilusión de que el mercado de los países americanos se abriera a los productos de dicho país europeo.

18 Juan Pablo II, 1979. Catechesi Tradendae. On Catechesis in Our Time. Libreria Editrice Vaticana, Ciudad Vaticana.

19 Sobre los parámetros interpretativos que una etiqueta puede imponer, véase Mason, 2014. Una cuestión de etiqueta. Éndoxa, Series Filosóficas, 33, pp. 165-180.

20 Palma, 2013. Fotografías de Martin Gusinde en Tierra del Fuego (1919-1924). La imagen material y receptiva. Ediciones Universidad Alberto Hurtado, Santiago, pp. 112 115.

2111 magen material y receptiva. Ediciones Universidad Alberto Hurtado, Santiago, pp. 112-115.

22 El Wiener Kreis o Círculo de Viena fue una corriente dentro de la antropología asociada con Schmidt y Frobenius, entre otros. 23 Sánchez Gómez, 2007, op. cit., pp. 74-75. 
Las catorce salas de exposición montadas en la Italia llevaban una carga digna de los pasajes comerciales celebrados por Walter Benjamin en su proyecto Das Passagen-Werk, concebido en París en la misma década ${ }^{24}$. De hecho, el manifiesto fue diseñado por Galileo Chini, quien al año siguiente contribuiría con dos paneles al pabellón italiano de la Exposition internationale des arts décoratifs et industriels modernes en París ${ }^{25}$. Armas de fuego Beretta, sombreros Borsalino, máquinas de escribir Olivetti y chocolate La Perugina viajaban junto con ametralladoras y un carro blindado a bordo de la nave que albergaba también una célula de Dante, una sala del siglo XIV, e incluso algunas reliquias situadas en urnas que contenían tierra sagrada que había sido bañada por la sangre italiana en las batallas de la guerra concluida en 1918. En los años del surrealismo, esta feria flotante recuerda los collages de un Max Ernst.

La sección del arte italiano fue comisionada al artista Giulio Aristide Sartorio (1860-1932), quien era también responsable de una parte de la decoración de la nave. La selección de cuadros expuestos en la sala del arte demuestra la misma heterogeneidad que la suma de las otras comodidades que llevaba la feria navegante: mientras que el único cuadro concedido por la Galería Nacional de Arte Moderno en Roma era La bañista de Ettore Tito, cuando la Italia zarpó de La Spezia el 18 de febrero de 1924 en un viaje que iba a durar ocho meses, llevaba cerca de quinientos cuadros que reflejaban el desarrollo del arte italiano desde 1850 hasta la contemporaneidad. Aunque los futuristas italianos no fueron representados en esa selección, el Ataque aéreo de Venecia, 1918 de Sartorio, en el cual, por encima de un horizonte muy bajo, los conos de luz de los reflectores de defensa antiaérea crean formas geométricas en el cielo, no está muy lejos de la predilección que

24 Benjamin, 2004. Libro de los pasajes. Traducción de Fernández Castañeda, Herrera y Guerrero, Akal, Madrid.

25 Benzi, 2002. Galileo Chini affreschista e decoratore. En Benzi (Ed.). Ad Vivendum. Galileo Chini. La stagione dell'Incanto. Affreschi e grandi decorazioni 1904-1942. Cat. exp. Terme Tamerici, Montecatini Terme, Mandragora, Florencia, pp. $11-107$, p. 65 y p. 89.

26 Sobre las vicisitudes de estos 61 cuadros, puestos a la venta por el Circolo Italiano di San Paolo en 1999, ver Miracco, 2006. Impressioni di una guerra vista e rappresentata dal pittore tra il 1917 e 1918. En Miracco (Ed.), Giulio Aristide sentía por la aerodinámica el movimiento futurista.

El cargamento de obras de arte incluía los sesenta y un cuadros de las batallas libradas en las tierras liberadas. Su autor, el propio Sartorio, había combatido y había sido llevado preso allí en 1915. Durante la estancia de la Italia en São Paulo, el círculo veneciano de la Casa d'Italia compró todos los cuadros de Sartorio en bloque ${ }^{26}$.

Junto a los cuadros embarcados antes de la salida de Italia, Sartorio continuaba pintando durante el viaje cuando las condiciones lo permitían. De esta producción de unos doscientos cuadros ${ }^{27}$, señalamos la presencia de treinta y ocho hechos entre el 4 y el 12 de junio, cuando la Italia estaba transitando por el estrecho de Magallanes. En el Estrecho la nave recaló en bahía Fortescue, donde los italianos encontraron a tres cazadores de nutrias alemanes cuyo refugio Sartorio inmortalizó en un cuadro, y en Punta Arenas. Es la única señal de una presencia humana en el Estrecho; todos los demás cuadros conocidos representan paisajes rocosos, glaciares y la fauna local.

Si la expedición italiana no produjo mucho impacto en los habitantes de Tierra del Fuego (y tampoco impresionó a los públicos en los puertos en que atracó, ni tan siquiera en Valparaíso y Antofagasta), se puede preguntar qué impresión Tierra del Fuego pudo producir en las mentes de los viajeros europeos. Parece que uno de los periodistas buscaba un salón de té en Tierra del Fuego, y el jefe de la expedición, Giovanni Giuriati, se lamentaba de que los pasajeros pasaran tanto tiempo durante la travesía con juegos de naipes: El pasaje del Atlántico al Pacífico señalará el pasaje del scopone al bridge $e^{28}$. Sería difícil imaginarse un contraste más fuerte con las penurias que sufrieron los tripulantes europeos de muchas de las naves que habían intentado atravesar el Estrecho en los siglos anteriores, llevando incluso al joven capitán

Sartorio 1860-1932. Cat. exp. Chiostro del Bramante, Roma, Mandragora, Florencia, pp. 129-137, pp. 136-137.

27 En 1926 fueron expuestos 101 en la Mostra d'Arte Marinara en la galería G. Michelazzi de Trieste, y unos noventa en The Anderson Gallery, Nueva York, en 1927, después de que casi desaparecieron del mercado del arte hasta la reunión de unos veinte en la muestra patrocinada por el Istituto Italo-Latino Americano en Roma en el invierno de 1999/2000.

28 Scopone es un juego de naipes italiano supuestamente derivado del juego español escoba. 
del Beagle, Pringle Stokes, a la desesperación y al suicidio en agosto de $1828^{29}$.

\section{FRAGMENTOS 1926-1927}

Aunque a bordo de la Italia había un capellán, el fascismo del que era representante el crucero dificultaba cualquier colaboración con el Vaticano. A pesar de todo, la inclusión del capellán refleja el esfuerzo de responder a las solicitudes de las misiones, sobre todo salesianas, en la región. En el mismo año de 1924 la congregación salesiana de Don Bosco envió flechas y otros objetos fueguinos al Museo di Colle Don Bosco en Asti, Italia, para participar en la muestra que estaba organizando el Vaticano para el Año Santo de 1925. El año siguiente de la muestra vaticana, es decir, en 1926, para no coincidir con ella, se organizó la Esposizione Missionaria Salesiana en Turín para celebrar el quincuagésimo aniversario de las misiones salesianas:

La ruta, que pasaba por dos edificios construidos para la ocasión, era poblada por estatuas, dioramas, animales disecados, fotografías, maquetas, dibujos, objetos de uso cotidiano, instrumentos, armas, ornamentos, textos de los institutos profesionales, curiosidades, recuerdos, muebles religiosos, objetos usados por los misioneros en el desempeño de sus actividades religiosas y de ayuda, conchas, fósiles, huevos, mariposas, escarabajos y herbarios ${ }^{30}$.

En resumen, la muestra daba la impresión de un colosal gabinete de curiosidades en que los objetos fueguinos compartían el mismo espacio que los fósiles y los animales disecados, es decir, fueron considerados como parte de la historia natural, parecido a la exposición en muchos

29 Chapman, 2010. European Encounters with the Yamana People of Cape Horn, Before and After Darwin. Cambridge University Press, Nueva York, pp. 97-105.

30 Forni, 2000. Culture e Missioni. Riflessioni su un museo etnologico missionario. En Remotti (Ed.). Memorie, Terreni, Musei. Contributi di antropologia, archeologia, geografia. Edizioni dell'Orso, Turín, pp. 239-254, p. 245.

31 Massa, 1945. Monografía de Magallanes. Sesenta años de museos de historia natural, como el Museo Nacional de Historia Natural de Chile, en el parque Quinta Normal, en la capital. Claro que tal estilo de exposición no ofrecía información alguna sobre la condición social y humana de los fueguinos en la época.

Este conocimiento del mundo austral fueguino, desde el mundo austral salesiano, ya estaba presente en la metodología de trabajo que los salesianos desarrollaron para dar vida al Museo Regional Salesiano Maggiorino Borgatello de Punta Arenas, inaugurado en 1893 con el nombre de Museo Territorial: Por más que los materiales del Museo empezaron a acumularse con anterioridad a 1890, con todo, no se expusieron en forma ordenada hasta el mes de Septiembre de $1893^{31}$. Su primer conservador fue el hermano coadjutor Ángel Gaudencio Benove, un naturalista autodidacta, a quien le tocó la tarea de ordenar materiales de diverso orden y origen, además de disponer la exhibición de diversas curiosidades que los misioneros traían de sus giras apostólicas y que pacientemente recolectaban con el fin de preservar algo de la historia y del medio de los pueblos o tolderías a los que llegaban ${ }^{32}$.

Este museo, en una primera etapa, funcionó en las salas de clases del Colegio San José, ordenando el padre Juan M. Aliberti, inspector salesiano de la Patagonia Meridional, Tierra del Fuego e islas Malvinas, su traslado en 1929 al Instituto Don Bosco. El padre Aliberti, quien también fue su director:

[...] hizo modelarpor el célebreartista piamontés, Señor Cellini, tres estatuas de tamaño natur[al] que representan al hombre, la mujer y el niño de la tribu Ona, con sus idénticas facciones y características que recordarán a las generaciones venideras los rasgos originales de una raza que va extinguiéndose, y que al mismo

acción Salesiana en el Sur 1886-1946. Escuela Tipográfica del Instituto Don Bosco, Punta Arenas, p. 514.

32 Museo Regional Salesiano Maggiorino Borgatello, 1992. Catálogo del Museo Regional Salesiano Maggiorino Borgatello (Colecciones Etnográficas, Antropológicas y Arqueológicas de las Etnias Aonikenk, Selk'nam, Kaweshkar, Yámana). Talleres Tipográficos del Instituto Don Bosco, Punta Arenas, pp. 12-13. 


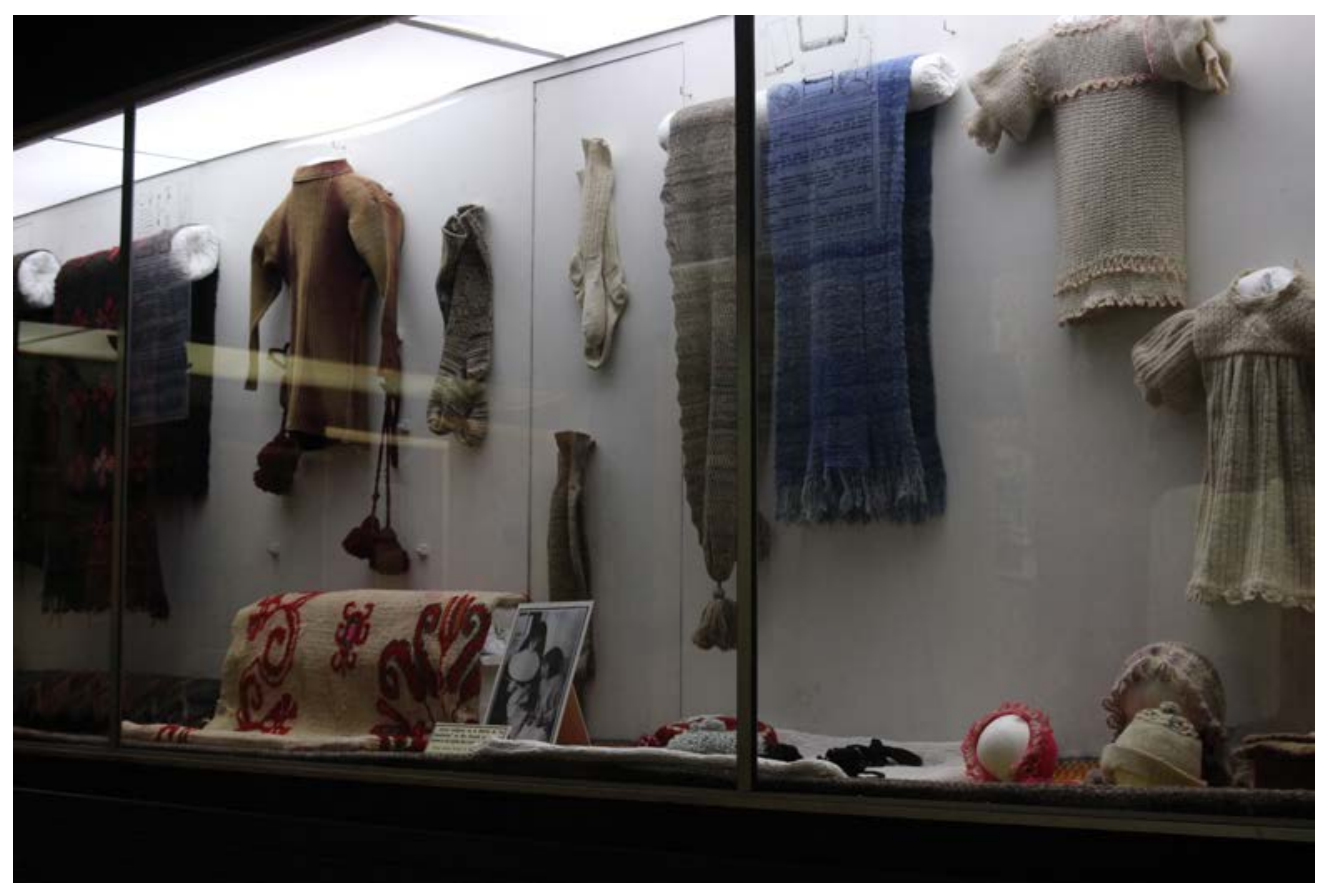

Fig. 2. Tejidos elaborados por mujeres indígenas de la Misión de San Rafael, isla Dawson. Fotografía de Nicolás Águila y Consuelo Tardones, Punta Arenas, 2019. Museo Maggiorino Borgatello, Punta Arenas.

tiempo pregona la obra civilizadora de los Misioneros Salesianos ${ }^{33}$.

En un catálogo del Museo del Colegio Salesiano en Punta Arenas, publicado el año 1906, se reconoce que la colección zoológica coexiste con la de moluscos, fósiles y aves. Y en la colección de plantas del mar, se observa una foto de tejidos, trabajos de indigenas de las misiones salesianas (Fig. 2 y Fig. 3), y una foto de una canoa de los indios alacalufes junto a una descripción de minerales ${ }^{34}$.

Muchos de estos objetos fueron elaborados en el espacio de la misión salesiana de San Rafael en isla Dawson ${ }^{35}$ :

33 Aliberti, 1946. Noticias históricas del Museo Regional Salesiano. IX Congreso Eucarístico Nacional de Magallanes, s.l., , p. 8.

34 Museo del Colegio Salesiano de Punta Arenas, 1906. Catálogo de colecciones magallánicas. Escuela Tipográfica del Colegio Pío IX, Buenos Aires, p. 43 y p. 46, respectivamente.

35 Isla situada en el estrecho de Magallanes, al sur de la actual ciudad de Punta Arenas.

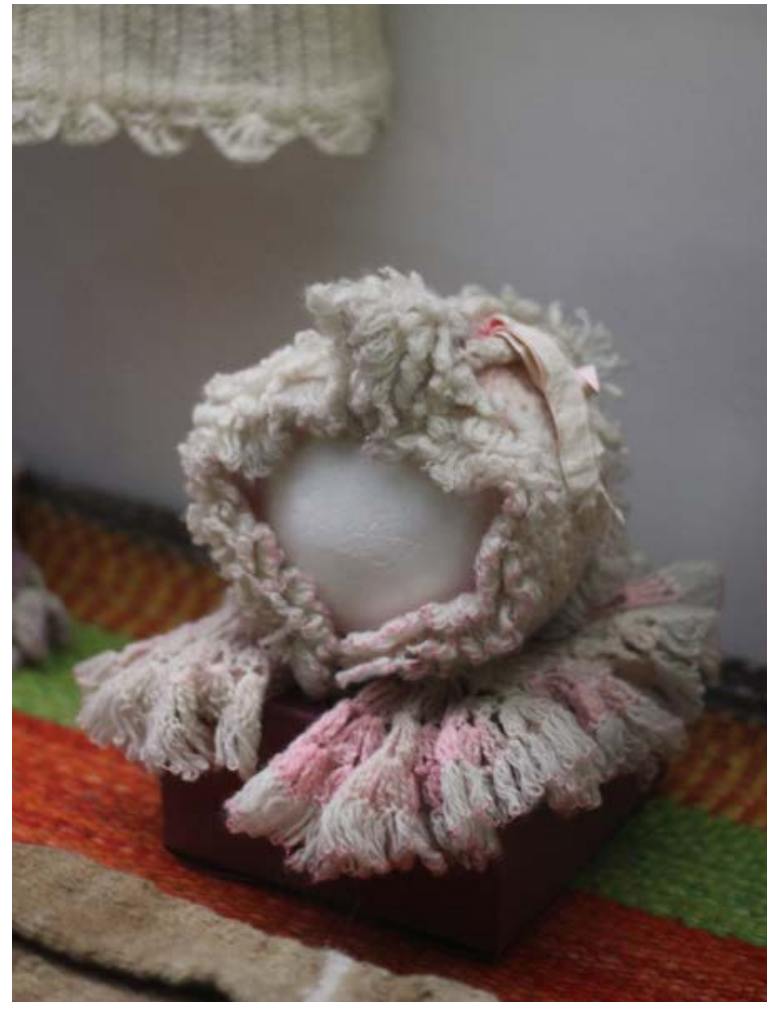

Fig. 3. Gorro de niña tejido por mujeres indígenas de la Misión de San Rafael, isla Dawson.

Fotografía de Nicolás Águila y Consuelo Tardones, Punta Arenas, 2019. Museo Maggiorino Borgatello, Punta Arenas. 
Inscripción 28, vaso de cuero de lobo, foca, isla Dawson. Inscripción 29, canastitas de las indias alacalufes, Dawson [...]. Inscripción 32, arpones grandes de los indios alacalufes, Dawson. Arpones chicos, Dawson [...]. Inscripción 39. Capa de cueros de coipo, trabajo de una india alacalufe de Dawson [...]. Inscripción 80, lazo con cuero de lobo trabajado por indios civilizados de la misión salesiana de Dawson $^{36}$.

Algunos de esos objetos fueron entregados al museo, como sucedió con una canoa kawésqar que recaló en las playas de Punta Arenas en abril de 1903:

[...] de esa frágil embarcación arribaron a Punta Arenas un hombre, una mujer con un niño de pecho, y algunos perros para reclamar de las autoridades locales la devolución de un niño de unos cinco años que algunos loberos les habian robado algunos días antes en la isla de Carlos III, en el estrecho de Magallanes. Las autoridades atendieron a sus justas peticiones haciéndole devolver a su hijo. Se embarcaron después sobre una goleta que estaba en punto de partir para aquellas partes, vendiendo dicha canoa al señor Roque Blaya ${ }^{37}$, el cual gentilmente la obsequió a este museo ${ }^{38}$.

Efectivamente el museo se fue transformando en el espacio que lo fue reuniendo todo en un lugar sin tiempo, el pasado, el presente y el futuro se encontraban en un mismo punto ${ }^{39}$ :

36 Cuaderno del Museo del Territorio de Magallanes (Salesiano), Sección Curiosidades de los indios,S.f. s.l.. Biblioteca del Museo Maggiorino Borgatello, Punta Arenas.

37 Notario público en Punta Arenas, en Aliberti, 1946, op. cit., p. 30.

38 Cuaderno del Museo del Territorio de Magallanes, s/f, op. cit.

39 Odone, 2006. El museo en el fin del mundo: ¿Una Historia también para la ciencia? Espacio Regional, Año 3(1), pp. 121-130.

40 Massa, 1945, op. cit., p. 514. En la Biblioteca del Museo Maggiorino Borgatello se encuentra una versión mecanografiada de la obra del sacerdote salesiano Lorenzo
Y como Monseñor [José Fagnano] ya caído en la cuenta de que las cuatro razas que poblaban su Prefectura Apostólica, pronto debian sucumbir y extinguirse, exterminadas por la peste blanca, que ya cundía entre ellos, y por otros factores, aconsejó al Padre Borgatello que se dedicara a recoger aquellos objetos más interesantes de su vida primitiva, con los que un día se pudiera reconstruir su historia y conservarla a través de los tiempos ${ }^{40}$.

Esta cita resulta particularmente interesante puesto que nos indica el duro momento que estaban viviendo las poblaciones fueguinas producto de la transmisión de enfermedades infecto-contagiosas, entre ellas la tisis o tuberculosis, la alfombrilla, el sarampión, entre las más frecuentes. Era ese contexto histórico que interpelaba a reunir y conservar la vida primitiva en las vitrinas del museo.

Se señala también que:

[...] niños y niñas de la misión de Dawson dejaron en el Museo Salesiano de Punta Arenas un exponente magnífico de su espíritu en las cartitas candorosas como el perfume de la inocencia, en los cuadernos de tareas escolares y de música bien escritos y dispuestos como los de cualquier Colegio Fiscal y en los tejidos [de las mujeres indígenas de la Misión de isla Dawson] de lana con que se adelantaron a los industriales de Tierra del Fuego ${ }^{41}$ (Fig. 4).

Massa (1945). Respecto del párrafo de la obra editada, en la versión mecanografiada se escribió del siguiente modo: Los indios, entonces muy numerosos, pero inficionados [sic] por la tisis, que los iba diezmando, estaban fatalmente destinados a desaparecer. Urgía conservar los recuerdos de estas razas próximas a extinguirse, y reunir todos aquellos objetos más interesantes de su vida primitiva, que nos los presentarán más tarde en una muda historia etnográfica conservada a través de los tiempos. Massa, sin fecha, Monografía de Magallanes. Sesenta años de acción Salesiana en el Sur 1886-1946, Versión mecanografiada, Museo Maggiorino Borgatello, Punta Arenas, p. 422.

41 Aliberti, 1946, op. cit., p. 10. 


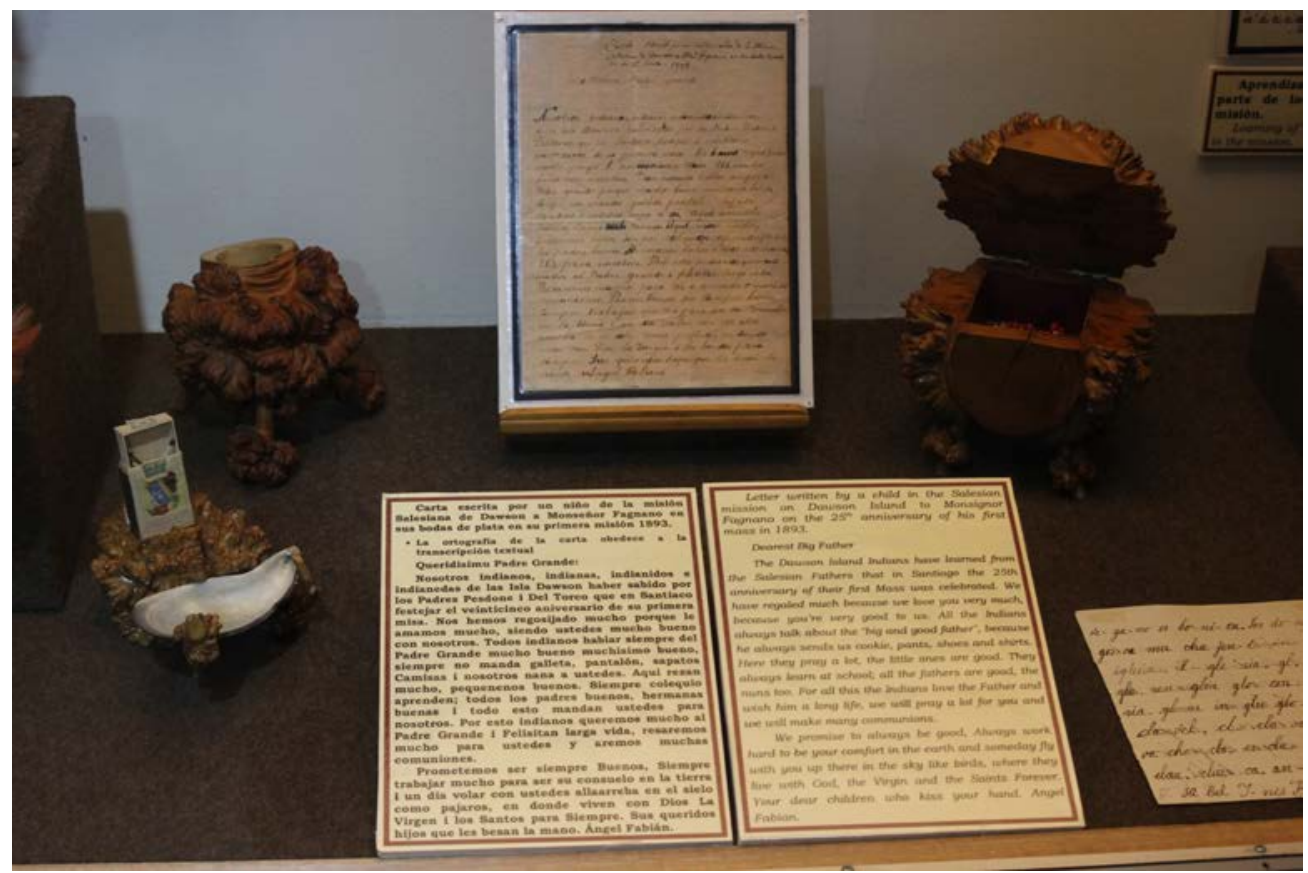

Fig. 4. Ejemplo de caligrafías de niños de la Misión de San Rafael, isla Dawson. Fotografía de Nicolás Águila y Consuelo Tardones, Punta Arenas, 2019.

Museo Maggiorino Borgatello, Punta Arenas.

Alli también se guardaron y exhibieron la:

[...] bandera de fantasía ideada y confeccionada por los Indios de la Misión de la Isla Dawson [...] Instrumentos de la primera Banda Musical compuesta de Indios de la Misión de Dawson que venía durante años a amenizar el acto patriótico del 18 de Septiembre, no habiendo otra en Punta Arenas [...] un juego de comedor hecho con nudo de Roble (Cittaria Darwinii) hechos en la Misión de Dawson ${ }^{42}$ (Fig. 5, Fig. 6 y Fig. 7).

El museo era por excelencia el lugar de la conservación de una conversación común en Tierra del Fuego:

-¿Usted es inglés? -me preguntóEn una época hubo muchos ingleses

43 Chatwin, 1977. Patagonia. Editorial Norma S.A., Buenos Aires, p. 161.

44 Odone y Palma, 2002. La muerte exhibida: fotografías de aquí. Dueños, gerentes capataces. Gente civilizada. Alemania, Inglaterra... iLa civilización! El resto... ¡Los Bárbaros! Esta estancia... el administrador siempre era inglés. Los indios mataban las ovejas. Los ingleses mataban a los indios. jJa, ja! ${ }^{43}$.

Ciertamente, matar indios fue algo muy común en la Tierra del Fuego ${ }^{44}$, una práctica que modeló la vida cotidiana de sus habitantes. Ovejeros escoceses $e$ ingleses, y buscadores del oro, transitaban y se asentaban, sobre todo en los sectores norte y centrales de la Isla Grande de Tierra del Fuego. Sus memorias quedaron impresas en diarios de viaje, como el caso del relato de William Blain. Ese relato nos habla de ovejas, caballos, perros, cururos, tierras estériles, estepas, montañas, playas y densos bosques. Los recuerdos que construye y representa William Blain se juegan en su presente, en medio de los indios que buscaban agua fresca en los arroyos, entre animales

Julius Popper en Tierra del Fuego (1886-1887). En Odone y Mason (Eds.). 12 Miradas sobre Selk'nam, Yáganes y Kawesqar. Taller Experimental Cuerpos Pintados, Santiago, pp. 261-314. 


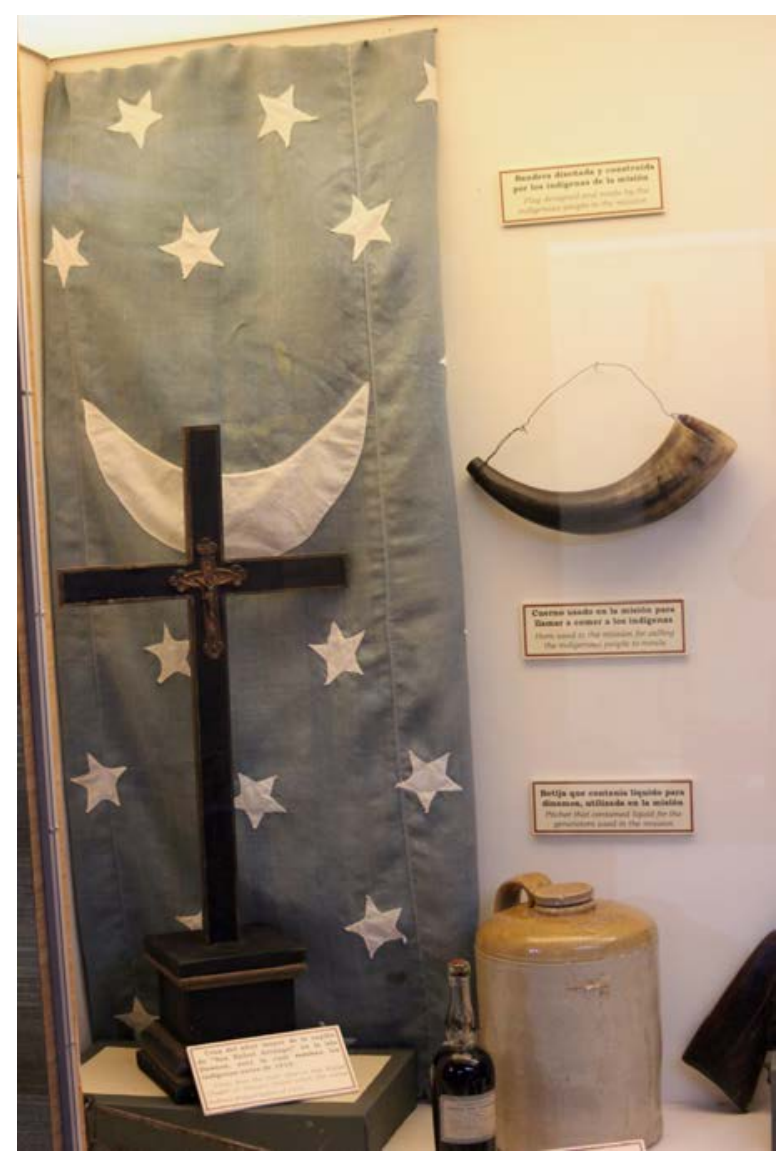

Fig. 5. Bandera de la Misión de San Rafael,

isla Dawson, elaborada por manos indígenas.

Fotografía de Nicolás Águila y Consuelo Tardones, Punta Arenas, 2019. Museo Maggiorino Borgatello, Punta Arenas.

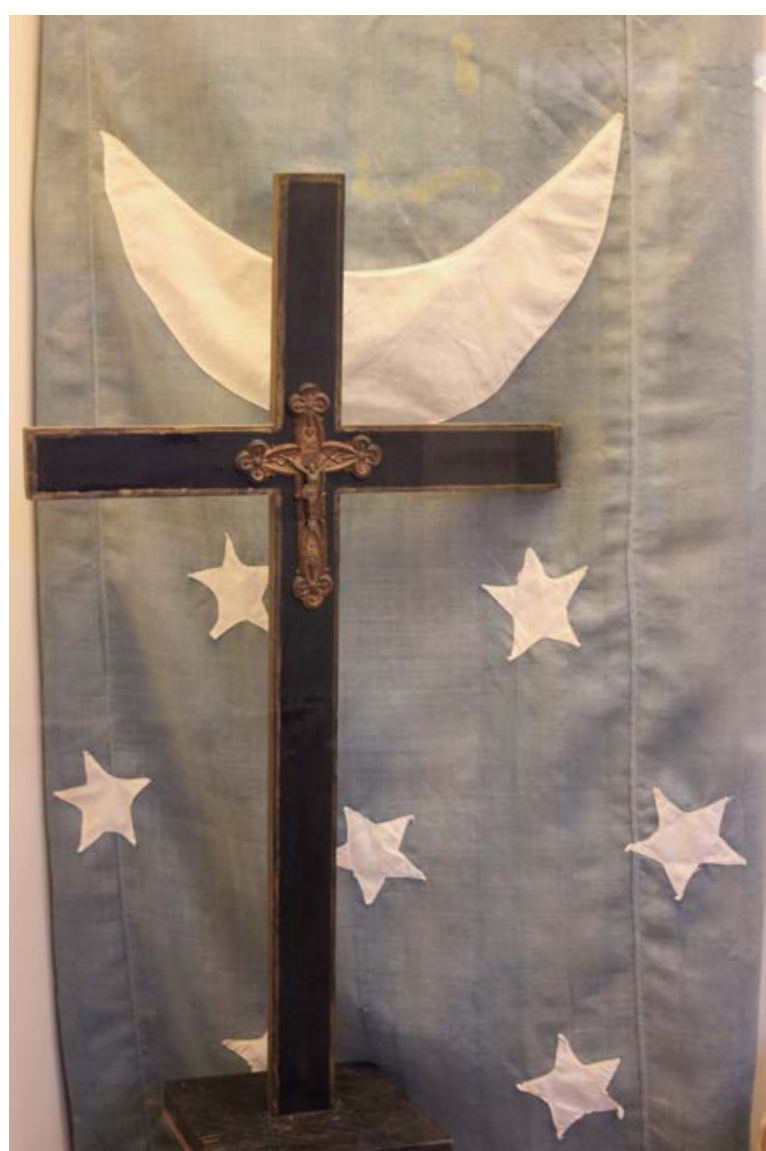

Fig. 6. Cruz del altar mayor de la capilla de la Misión de San Rafael, isla Dawson.

Fotografía de Nicolás Águila y Consuelo Tardones, Punta Arenas, 2019. Museo Maggiorino Borgatello, Punta Arenas.

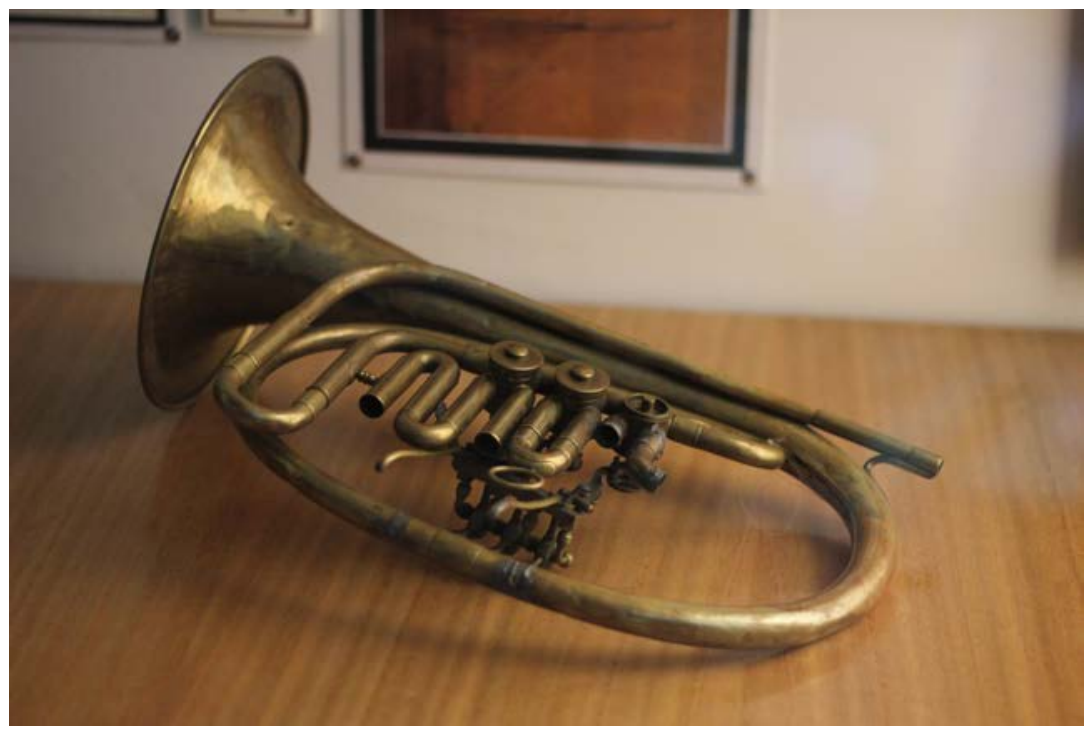

Fig. 7. Instrumento musical de la banda indígena de la Misión de San Rafael.

Fotografía de Nicolás Águila y Consuelo Tardones, Punta Arenas, 2019. Museo Maggiorino Borgatello, Punta Arenas. 
y hombres perdidos, inquietos y asustados. Rodeados de cercas de alambre y órdenes de despejar los alrededores del campamento de hombres, mujeres y niños indios, en algunos casos se derramaba sangre humana. Su memoria se fija en las provisiones que escaseaban, en los momentos en que solo quedaban pequeñas cantidades de arroz y té, y muchas veces nada de azúcar. Alli se registran hombres tirados boca abajo, tipos que pateaban en la cara con un par de botas con clavos. Y piojos rastreros que también se alojaban en los cuerpos de los blancos durante meses:

Septiembre 13. Tuve noticias de que los caballos del River Side estaban perdidos y envié 4 hombres y caballos para buscarlos. El 16 los hombres regresaron con los caballos perdidos y 3 niños indios. Su introducción a la civilización fue como sigue: primero, con un par de tijeras para ovejas, su pelo fue recortado tan cerca de la piel como las tijeras podian cortar. Luego, fueron llevados a los baños de inmersión con cepillos para zapatos, y fueron efectivamente refregados con el baño de ovejas (sin venenos por supuesto). Esto era para matar los parásitos. Luego fueron terminados con jabón y agua. Con ropas viejas de los hombres fue cubierta su desnudez por primera vez en sus vidas. Ellos estaban muy temerosos del rifle. La consecuencia de huir estaba bien impresa en sus jóvenes mentes. En un corto tiempo se acostumbraron a estar en casa entre nosotros ${ }^{45}$.

En sus memorias se cuelan los vientos y el pastoreo, los tiempos de las pasturas y la esquila. Alli se suceden los días en que nada sucede y que sin embargo resultan tan ocupados que no hay tiempo para escribir, los días de café, licor y delirios de borrachera. Allí están los suministros robados de los barcos naufragados, sus tiempos de quedarse en casa, cocinando y lavando un poco de ropa. En

45 Harambour, 2016. Un viaje a las colonias. Memorias y Diario de un ovejero escocés en Malvinas, Patagonia y Tierra del Fuego (1878-1898). Traducción de Azara, M. y Harambour, A.. Fuentes para la Historia de la República. Volumen XLII, Centro de Investigaciones Diego Barros Arana, Santiago, p. 100.

46 Odone, 2006, op. cit.
Blain, la Tierra del Fuego-Patagónica se siente dura y oxidada como el hierro, y no solo por las heladas, las nieves y las escarchas, sino que por la violencia, que en sus distintas formas lo cubre todo.

Estas memorias del diario de un ovejero escocés en Tierra del Fuego son un viaje múltiple por el colonialismo de asentamiento, esa especie de máquina de guerra caníbal de recursos, seres humanos, objetos y territorios. Alli se reconocen sucesos que para algunos pueden adscribirse a experiencias históricas de exterminio y para otros caben en la categoría de genocidio.

El Museo Salesiano Maggiorino Borgatello reunía en un solo lugar el pasado, el presente y el futuro de la vida animal, vegetal y humana de Tierra del Fuego. Había allí un discurso sobre la ciencia, la razón y la civilización, el museo capturaba el tiempo y lo detenía, para preservarlo para la posteridad, puesto que ya la extinción estaba decretada ${ }^{46}$.

Bien podría pensarse que las colecciones contienen una suerte de luchas en curso, que traen aparejadas el no consenso, los no re-conocimientos, y donde también se ponen en juego los procesos de formación del pensamiento, en este caso europeo. Al menos, estos objetos nativos de Tierra del Fuego dan cuenta de esos ensamblajes híbridos de lo europeo en lo fueguino. En esos objetos que reposan en las colecciones de museos y personas hay una performance de la pérdida de sus contextos de uso y circulación. Desde esta perspectiva, y para el caso de Tierra del Fuego:

[...] lacolecciónes, de alguna manera, el reflejo de un contacto asimétrico entre culturas enormemente diferenciadas. Hombres que entregan objetos amados, repletos de profundos significados que se ignoran [...]. Una cultura que entrega objetos, imposibilitada siquiera de intuir los motivos autodestructivos del acto y otra cultura que los recibe, fascinada, a pesar de su origen abominable $e^{47}$.

47

Quiroz y Olivares, 2008. El texto roto: Fragilidad, itinerarios y la transformación de los objetos de alteridad [antropología poética de las colecciones etnográficas]. En Gallardo y Quiroz (Eds.). Un almuerzo desnudo. Ensayos en cultura material, representación y experiencia poética. Universidad Academia de Humanismo Cristiano, Santiago, pp. 145-156, p. 147. 
En abril del año 1927, ya cerradas tanto la Esposizione Universale Missionaria como la Esposizione Missionaria Salesiana, llegó al Vaticano entre otros objetos una gran tira de cuero para cubrir la cabaña; a la cual se añaden numerosos bastones ${ }^{48}$. Fueron enviados por Martin Gusinde del Colegio S. Gabriel de Mödling (Viena) ${ }^{49}$, en nombre de la Sociedad del Verbo Divino, para la exposición permanente del Museo Missionario Etnologico, cuyo director, Wilhelm Schmidt, era otro miembro de la misma orden. Tal como el modelo de la cabaña ritual, estos materiales para reconstruir una cabaña -esta vez no de los yámana, sino de los selk'namestán enclaustrados en el depósito de los Museos Vaticanos. En este caso, la reconstrucción misma ha cambiado el aspecto físico: mientras que el toldo selk'nam era por lo general una construcción bajita, provisoria y más o menos cónica, construido de modo sencillo con palos trabajados de antemano y ramas $^{50}$, resulta difícil distinguir entre el toldo reconstruido en Roma $y$ un esbelto tipi norteamericano. Ya en el siglo XVI las faldas y los tocados de plumas de algunas etnias brasileñas habían penetrado en la imagen de los indígenas norteamericanos ${ }^{51}$. En este ejemplo de las primeras décadas del siglo XX, el rumbo se ha invertido en el uso de un modelo norteamericano para caracterizar una vivienda fueguina.

Ciertamente, todo está invertido en la historia de los objetos y los nativos de Tierra del Fuego, considerando además que por esos años ya comenzaba a perfilarse un rico mercado de artesanía indígena, donde los objetos estaban totalmente separados de sus contextos de uso: los arcos ya no servían ni se usaban para cazar guanacos ${ }^{52}$. Algo similar ocurre con los trozos o

48 Console, 2006, op. cit., p. 307.

49 El mismo colegio ya había enviado 85 objetos para la Esposizione en 1924, año en que Martin Gusinde volvió del último de sus cuatro viajes a Tierra del Fuego.

50 Chapman, 1986. Los selk'nam. La vida de los onas. Emecé Editores, Buenos Aires, p. 49.

51 Mason, 1993. Escritura fragmentaria: aproximaciones al otro. En Gossen, Klor de Alva, Gutiérrez Estévez y LeónPortilla (Eds.). De Palabra y Obra en el Nuevo Mundo. Vol. 3, La formación del otro. Siglo XXI de España, Madrid, pp. 395-430.

52 Bascopé, 2009. De la exploración a la explotación. Tres tiras de cueros enviadas a Roma en 1927, ellas tampoco servían para cubrir las viviendas rituales de los selk'nam de Tierra del Fuego, aunque sí para la recreación de su réplica en Europa.

Los fragmentos presentados aquí demuestran la importancia del contexto. No solo la selección de los artefactos para ser enviados a Europa, sino también el entorno físico y el modo en que se presentan una vez llegados allí, influyen de modo decisivo en la recepción del público que los observa. Y viceversa, la percepción de los europeos que se encuentran o pasan por la Tierra del Fuego está condicionada por el modo de autopresentación de ellos mismos, tal y como se observa en la colección del Museo Maggiorino Borgatello de Punta Arenas o en el museo flotante la Italia. Se producen entonces huellas mnémicas en la superficie de la pizarra mágica cuyos caracteres pueden ser borrados tan pronto como se registren nuevas noticias en la misma superficie. Permanecen relativamente duraderas hasta que se reemplazan. Duraderas como las rocas de la Tierra del Fuego, temporales como las grandes olas del estrecho de Magallanes.

\section{EPÍLOGO}

En los últimos años de la década de 1920, algunos eventos culturales innovadores realizados en París coincidieron con un verdadero estallido del surrealismo en la capital francesa. En 1928 el pianista de jazz más tarde conocido por sus trabajos museísticos Georges-Henri Rivière y el antropólogo suizo Alfred Métraux organizaron una exposición revolucionaria cuando presentaron piezas precolombinas de alta calidad al público parisino ${ }^{53}$. La muestra estimuló a varios artistas y escritores de los

notas sobre la colonización de la Patagonia austral. Nuevo Mundo Mundos Nuevos [En línea], Coloquios, Puesto en línea el 06 julio 2009, consultado el 30 enero 2019. URL: http://journals.openedition.org/nuevomundo/56645; DOI: $10.4000 /$ nuevomundo.56645.

53 La exposición Les Arts Anciens de l'Amérique fue celebrada en el Musée des Arts Décoratifs. Sobre la exposición y la historia de la apreciación estética de los artefactos precolombinos, véase Braun, 1993. Pre Columbian art and the post-Columbian world. Harry N. Abrams, New York. 
círculos surrealistas a la hora de explorar el arte precolombino. Fue una provocación para cuestionar las categorías estéticas implícitas en la distinción entre artefacto etnográfico y artefacto artístico que tiene una larga historia. Un hito en esa historia fue la controvertida exposición Primitivism in 20th Century Art. Affinity of Tribal and Modern, celebrada en Nueva York en 1984, aunque extrañamente el curador William Rubin excluyó al mundo precolombino ${ }^{54}$. La nueva manera en que Rivière y Métraux presentaron sus materiales los alineaba con los surrealistas. Rivière dio el siguiente paso en su reto a la museología tradicional cuando invitó a Georges Bataille a editar la revista Documents en 1929. Bajo la mirada de quienes escribían en esta revista, cualquier artefacto etnográfico se convertía automáticamente en objeto de valor estético ${ }^{55}$.

¿Y en Italia, el surrealismo había sobrevivido a la instalación de la dictadura fascista el 3 de enero del año 1925? De todas maneras. Antes del año 1930 el salesiano Alberto Maria De Agostini realizó el largometraje Terre Magellaniche, artistico film dal vero -el título en español era Tierra del Fuego, el film más artístico, pintoresco e instructivo de nuestro lejano sur- cuyo póster italiano mostraba una fila de pingüinos encabezada por uno llevando una cámara de cine por las nieves (Fig. 8). El parentesco íntimo entre Tierra del Fuego y el surrealismo parisino -separados por más de 13.000 kilómetros de distancia- parece haber sido caracterizado por esa relación de atracción $e$ influencia recíproca que conocemos bajo el nombre de afinidad electiva ${ }^{56}$. Esa relación que reúne a algo con algo, objetos, personas, animales, conocimientos, recuerdos, en fin, una Tierra del Fuego y el movimiento surrealista, los fueguinos y los hermanos salesianos, las exposiciones y sus museos, todos ellos con sus lazos de simpatías, amistades y amores que están avenidos, aunque sean desiguales.

54 Rubin (Ed.), 1984. "Primitivism" in Modern Art: Affinity of the Tribal and the Modern. Museum of Modern Art, New York, 2 tomos.

55 Tythacott, 2003. Surrealism and the Exotic. Routledge, Londres y Nueva York.

56 Goethe, 2012 [1809]. Las afinidades electivas. Tr. Tenreiro

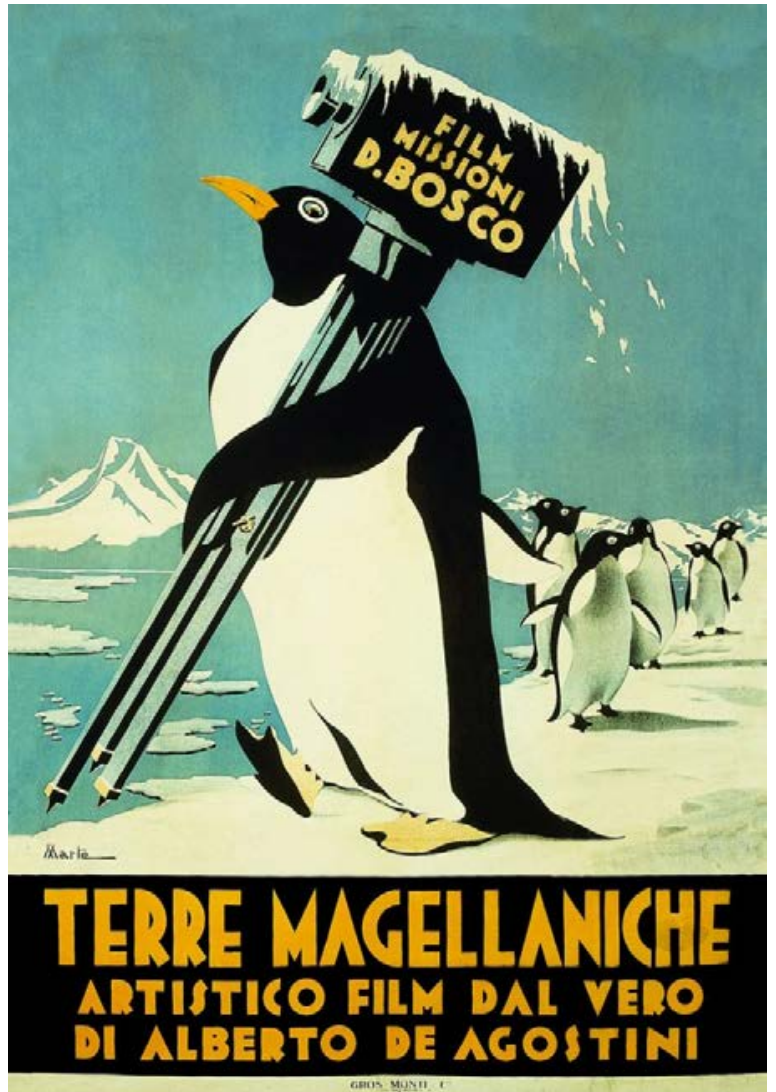

Fig. 8. Póster en la versión italiana del largometraje Terre Magellaniche, artistico film dal vero de Alberto Maria De Agostini, estrenado por primera vez en Turín en mayo 1933.

\section{BIBLIOGRAFÍA}

AA.VV. (2000). Chile 100 años artes visuales. Catálogo de exposición. Santiago: Museo Nacional de Bellas Artes.

Aliberti, J. M., Pbro. (1946). Noticias históricas del Museo Regional Salesiano. IX Congreso Eucarístico Nacional de Magallanes, s.1., 6-30.

Bascopé, J. (2009). De la exploración a la explotación. Tres notas sobre la colonización de la Patagonia austral, Nuevo Mundo Mundos Nuevos [En línea], Coloquios, Puesto en línea el 06 julio 2009, consultado el 30 enero 2019. URL: http://journals.openedition. org/nuevomundo/56645; DOI: $10.4000 /$

Rodríguez, Clásicos Galema, Buenos Aires. Benjamin publicó un largo ensayo dedicado a Las afinidades electivas de Goethe en 1924-25, véase Benjamin, 1996. Selected Writings. Bullock y Jennings (Eds.). Vol. 1 19231926. Belknap Press, Cambridge y Londres, pp. 297-360. 
nuevomundo. 56645

Benjamin, W. (1996). Selected Writings. M. Bullock \& M. W. Jennings (Eds.). Vol. 1 1923-1926. Cambridge y Londres: Belknap Press.

Benjamin, W. (2004). Libro de los pasajes. Madrid: Akal.

Benton, C., Benton, T., \& Wood, G. (Eds.) (2003). Art Deco 1910-1939. Catálogo de exposición. Victoria \& Albert Museum Londres. Londres: V\&A Publications.

Benzi, F. (2002). Galileo Chini affreschista e decoratore. En Benzi, F. (Ed.), Ad Vivendum. Galileo Chini. La stagione dell'Incanto. Affreschi e grandi decorazioni 1904-1942. Catálogo de exposición. Terme Tamerici, Montecatini Terme (pp. 11-107). Florencia: Mandragora.

Braun, B. (1993). Pre-Columbian art and the post-Columbian world. New York: Harry N. Abrams.

Chapman, A. (1986). Los selk'nam. La vida de los onas. Buenos Aires: Emecé Editores.

Chapman, A. (1997). The Great Ceremonies of the Selk'nam and the Yámana. A Comparative Analysis. En C. McEwan, L. A. Borrero \& A. Prieto (Eds.), Patagonia. Natural History, prehistory and ethnography at the Uttermost End of the Earth (pp. 82-109). London: British Museum Press.

Chapman, A. (2002). Fin de un mundo. Los selknam de Tierra del Fuego. Santiago de Chile: Taller Experimental Cuerpos Pintados.

Chapman, A. (2010). European Encounters with the Yamana People of Cape Horn, Before and After Darwin. Nueva York: Cambridge University Press.

Chatwin, B. (1977). Patagonia. Buenos Aires: Editorial Norma S.A.

Console, E. (2006). Le collezioni della Terra del Fuoco del Museo Missionario Etnologico Vaticano. En A. Salerno \& A. Tagliacozzo (Eds.). Finis Terrae. Viaggiatori, esploratori e missionari italiani nella Terra del Fuoco. Catálogo de exposición. Museo Nazionale Preistorico Etnografico "Luigi Pigorini", Roma (pp. 295-309). Roma: Ministero per i Beni e le Attività Culturali.

Cuaderno del Museo del Territorio de Magallanes (Salesiano): Sección Curiosidades de los indios. S.f, s.l. Punta Arenas: Biblioteca del Museo Maggiorino Borgatello.

Forni, S. (2000). Culture e Missioni. Riflessioni su un museo etnologico missionario. En F. Remotti (Ed.). Memorie, Terreni, Musei. Contributi di antropologia, archeologia, geografia (pp. 239-254). Turín: Edizioni dell'Orso,.

Freud, S. (1979 [1924]). Nota sobre la "pizarra mágica". Obras Completas. Vol. XIX. El yo y el ello, y otras obras
(1923-1925). Buenos Aires y Madrid: Amorrortu.

Goethe. J. W. (2012 [1809]). Las afinidades electivas. Traducción de Tenreiro Rodríguez, R. Buenos Aires: Clásicos Galema.

Harambour, A. (2016). Un viaje a las colonias. Memorias y Diario de un ovejero escocés en Malvinas, Patagonia y Tierra del Fuego (1878-1898). Traducción de Azara, M. \& Harambour, A., Fuentes para la Historia de la República. Volumen XLII. Santiago de Chile: Centro de Investigaciones Diego Barros Arana.

Hawkins, J. (1984). Inverse Images: the meaning of culture, ethnicity and family in Postcolonial Guatemala. Albuquerque: University of New Mexico Press.

Johnson, S. \& Boswell, J. (1976). Journey to the Hebrides. Edinburgh: Canongate.

Juan Pablo II (1979). Catechesi Tradendae. On Catechesis in Our Time. Ciudad Vaticana: Libreria Editrice Vaticana.

Mason, P. (1990). Deconstructing America. Representations of the Other. Londres y Nueva York: Routledge.

Mason, P. (1993). Escritura fragmentaria: aproximaciones al otro. En G. H. Gossen, J. J. Klor de Alva, M. Gutiérrez Estévez \& M. León-Portilla, M. (Eds.), De Palabra y Obra en el Nuevo Mundo, Vol. 3, La formación del otro (pp. 395-430). Madrid: Siglo XXI de España.

Mason, P. (2014). Una cuestión de etiqueta. Éndoxa, Series Filosóficas, 33, 165-180.

Massa, L. (1945). Monografía de Magallanes. Sesenta años de acción Salesiana en el Sur 1886-1946. Punta Arenas: Escuela Tipográfica del Instituto Don Bosco.

Massa, L. (s.f.). Monografía de Magallanes. Sesenta años de acción Salesiana en el Sur 1886-1946. Punta Arenas: Versión mecanografiada, Museo Maggiorino Borgatello.

Miracco, R. (2006). Impressioni di una guerra vista e rappresentata dal pittore tra il 1917 e 1918. En R. Miracco (Ed.), Giulio Aristide Sartorio 1860-1932. Catálogo de exposición. Chiostro del Bramante, Roma (pp. 129-137). Florencia: Mandragora.

Murlender, L. (2014). La escuela de Joaquín Torres-García y su tesis americanista: Buscar a América. Diversidad, 9, 5, 43-59.

Museo del Colegio Salesiano de Punta Arenas (1906). Catálogo de colecciones magallánicas. Buenos Aires: Escuela Tipográfica del Colegio Pío IX.

Museo Regional Salesiano Maggiorino Borgatello (1992). Catálogo del Museo Regional Salesiano Maggiorino Borgatello (Colecciones Etnográficas, Antropológicas y Arqueológicas de las Etnias Aonikenk, Selk'nam, Kaweshkar, Yámana). Punta Arenas: Talleres 
Tipográficos del Instituto Don Bosco.

Odone, C. (2006). El museo en el fin del mundo: ¿Una Historia también para la ciencia? Espacio Regional, 3(1), 121130.

Odone, C., \& Palma, M. (2002). La muerte exhibida: fotografías de Julius Popper en Tierra del Fuego (1886-1887). En C. Odone \& P. Mason (Eds.), 12 Miradas sobre Selk'nam, Yáganes y Kawesqar (pp. 261-314). Santiago: Taller Experimental Cuerpos Pintados.

Pagnotta, Ch. (2018). La Exposición Misional Vaticana de 1925, los misioneros salesianos y la representación del Oriente ecuatoriano. Procesos: Revista ecuatoriana de Historia, 47, 59-88.

Palma, M. (2013). Fotografías de Martin Gusinde en Tierra del Fuego (1919-1924). La imagen material y receptiva. Santiago: Ediciones Universidad Alberto Hurtado.

Penhos, M. (2005). Ver, conocer, dominar. Imágenes de Sudamérica a fines del siglo XVIII. Buenos Aires: Siglo Veintiuno Editores.

Penhos, M. (2018). Paisaje con figuras. La invención de Tierra del Fuego a bordo del Beagle (1826-1836). Buenos Aires: Ampersand.

Quiroz, D., \& Olivares, J. C. (2008). El texto roto: Fragilidad, itinerarios y la transformación de los objetos de alteridad [antropología poética de las colecciones etnográficas]. En F. Gallardo \& D. Quiroz (Eds.), Un almuerzo desnudo. Ensayos en cultura material, representación y experiencia poética (pp. 145-156). Santiago: Universidad Academia de Humanismo Cristiano.

Rubin, W. (Ed.) (1984). "Primitivism" in Modern Art: Affinity of the Tribal and the Modern, 2 Tomos. Nueva York: Museum of Modern Art.

Sánchez Gómez, L. A. (2007). Por la etnología hacia Dios: La Exposición Misional Vaticana de 1925. Revista de Dialectología y Tradiciones Populares, LXII(2), 63107.

Sánchez Gómez, L. A. (2012). Espectáculos de dominación y fe: las exposiciones etnológicas-misionales de las Iglesias Cristianas (1851-1958). Ayer, 87, 133-162.

Sosa, N. (2015). Cazadores de plumas en la Patagonia. Singulares intercambios entre Tehuelches y Cristianos. Buenos Aires: Patagonia Sur Libros.

Sterne, L. (1967 [1759-1767]). The Life \& Opinions of Tristram Shandy. Harmondsworth: Penguin Books.

Tythacott, L. (2003). Surrealism and the Exotic. Londres y Nueva York: Routledge. 